\title{
Parents' perceptions of health and physical activity needs of children with Down syndrome
}

\section{Kristi Sayers Menear}

Individuals with Down syndrome typically have low fitness levels and obesity despite data that indicate physiological gains from physical activity and exercise interventions. Low fitness levels and obesity in individuals with Down syndrome may be related to sedentary lifestyles, social and recreational opportunities, or low motivation to be physically active. These causal influences on the overall health of individuals with Down syndrome may be related to parental or caregiver support. Through this study, parents of children with Down syndrome from preschool to adolescent ages were interviewed about their perceptions of the health and physical activity needs of their children. Data from four focus groups indicated the following most salient themes: (1) all parents believed participation in physical activity has immediate and long-term positive health impacts on their child with Down syndrome, and most of the parents thought their child would benefit from being more physically active, (2) most parents observed that their child participated in physical activities primarily for social reasons, most notably to be with their peers with or without Down syndrome or to be with their sibling(s), and that without such motivation their child would choose sedentary activities, (3) parents of teenagers identified a need for their child to learn an individual sport to have sporting opportunities that do not require ability-matched teammates and opponents, and (4) parents recognised their need for help from physical activity specialists through either parent education regarding home-based physical activity programmes or an increase in appropriate community-based physical activity programmes for their child with Down syndrome. The interview data suggest future research should evaluate the outcomes of long-term individualised home-based physical activity interventions for children with Down syndrome. Additionally, educators, recreation specialists, and therapists should assist children and youth with their acquisition of skills used in individual and dual sports.

Research indicates low fitness levels in individuals with Down syndrome ${ }^{[1-5]}$. There is also a prevalence of obesity in children, adolescents, and adults with Down syndrome ${ }^{[6-10]}$.

Low fitness levels and obesity in individuals with Down syndrome may be related to sedentary lifestyles ${ }^{[11-14]}$, social and recreational opportunities ${ }^{[15]}$, or low motivation to be physically $\operatorname{active}^{[16]}$.

\section{Benefits from physical activity or exercise}

Several studies have indicated positive benefits from participation in physical activity or exercise by individuals with Down syndrome. Balic, Mateos, Blasco and Fernhall ${ }^{[17]}$ studied individuals with Down syndrome who were participants in Special Olympics and were physically active 4.9 hours per week for at least 1 year. The participants exhibited higher aerobic capacity, muscular strength, and power than sedentary individuals with Down syndrome. Similarly, a study by Tsimaras and Fotiadou ${ }^{[18]}$ found that adults with Down syndrome improved their strength and balance following a 12-week training programme. Rimmer and colleagues ${ }^{[49]}$ found significant improvements in the cardiovascular fitness and muscle strength and endurance of adults with Down syndrome who participated in a cardiovascular and strength exercise training programme. Other studies also showed improvements in muscle strength following training programmes for individuals with Down syndrome ${ }^{[19,20]}$. Draheim, Williams and McCub-
University of Alabama at Birmingham, Dept. of Human Studies, Birmingham, AL

Correspondence to Kristi Sayers Menear•e-mail:kmenear@uab. edu

doi:10.3104/reports.1996

(c) 2007 The Authors. Journal Compilation @ 2007 The Down Syndrome Educational Trust. 
bin $^{[50]}$ found reduced risk of hyperinsulinemia and abdominal obesity in adults with mental retardation (with and without Down syndrome) who were moderately to vigorously physically active at least five days per week and consumed lower dietary fat intakes. Together, these studies suggest that physical activity or exercise training can increase physical fitness in individuals with Down syndrome.

\section{Barriers to participation}

If individuals with Down syndrome experience low fitness levels despite data-based evidence to indicate positive fitness gains from participation in physical activity and exercise, is it because they do not participate in physical activity or exercise often enough? Heller, Hsieh and Rimmer ${ }^{[21]}$ found that individuals with Down syndrome experience high costs, lack of transportation, difficulty accessing equipment and fitness facilities, and difficulty finding experienced personnel to train them. Heller, Hsieh and Rimmer ${ }^{[22]}$ reduced these barriers by providing a centre-based programme and found the experimental group experienced more positive attitudinal and psychosocial outcomes and fewer cognitive-emotional barriers. The researchers did not assess adherence or longterm benefits.

Jobling ${ }^{[23]}$ described commonalities of individuals with Down syndrome which may be viewed as barriers to participation in active leisure opportunities. The commonalities included perceptions of difference, perceptions of motor skill delays, lack of practice, obesity, and inactivity. Though acknowledging these commonalities as challenges to develop opportunity rather than barriers to participation in physical activity, Jobling described two programmes from Australia whereby sport and recreation opportunities were provided for children and adults with Down syndrome through community-based programmes.

Frey, Buchanan and Rosser Sandt ${ }^{[24]}$ used interpretive ethnography to examine perceptions of physical activity behaviour of 12 adults with mild mental retardation. Multiple data sources, including information from four parents and two job supervisors, indicated two themes unique to this group: (1) a need for specially designed programmes, and (2) a need for support system providers to know and understand the importance of physical activity for these individuals.

\section{Parental support of physical activity}

Research has shown a connection between parent support and their children's participation in physical activity ${ }^{[25,26]}$. Parent support may come in the form of positive role models, transportation, payment of fees, providing encouragement or motivation ${ }^{[27]}$. The physical activity levels of children's parents and siblings have a positive influence on their own participation in physical activity, just as the modelling of sedentary behaviours by parents and siblings influences a development of a sedentary lifestyle in children ${ }^{[28-30]}$. When children learn an appreciation for physical activity and when they learn how to participate in physical activities, they tend to be more physically active than their peers who are simply exposed to physical activity ${ }^{[31]}$.

\section{The study}

The purpose of this study was to investigate parents' perceptions of the health and physical activity needs of their children with Down syndrome.

\section{Methods}

A purposeful sampling technique was used to recruit parent participants ${ }^{[32]}$. A research announcement flyer was mailed by the organisation Parent Advocates for Down Syndrome, located in a metropolitan area of the southeastern United States. Potential participants called the investigator for more information about the study. Interested parents were divided into three focus groups according to the ages of their children (preschool, elementary, adolescent); a fourth focus group of parents of children who were preschool - adolescent age was formed for parents who were not able to meet at the times and locations of the other focus groups. Focus group interviews were scheduled for places and times that were convenient to the majority of participants.

At the beginning of each focus group interview, participants were again told of all aspects of the project, a process Kvale ${ }^{[33]}$ refers to as "framing" the interview. They gave their written consent to participate in the project along with information needed for them to receive their participant compensation ( $\$ 75$ for completing the interview, $\$ 25$ for returning the transcript of the interview). Then, in order to establish some comfort in the setting, the investigator asked each participant to introduce himself/herself, describe his/her child, and share a recent story about when the child made him/her laugh. Following this, participants were reminded the tape recorder would be turned on during the interview but could be turned off upon request. The same set of guiding questions was used for each focus group. The investigator gave a 5-second pause after similar comments, thus allowing for additional comments before asking another question, and appropriate probing questions were asked as needed ${ }^{[34]}$. The investigator attempted to end each interview within 
one hour.

An audit trail was kept of all work completed with the interview data ${ }^{[35]}$. The investigator transcribed the interview tapes verbatim within 48 hours of each focus group interview. Data analysis notes made while transcribing were stored in a separate file. The transcripts were mailed to the participants within two days of each interview. To ascertain the trustworthiness of the transcripts ${ }^{[36]}$, participants conducted member checks of the transcripts and returned them to the investigator in the self-addressed stamped envelopes provided. Through the member checks, the participants proof read the transcripts for accuracy and, if they desired, wrote comments to clarify statements they made during the interview. After receiving the transcripts from the participants, the investigator read the participants' comments and added relevant notes to the data analysis file. Then, the investigator took a break from the research study to gain distance from the participants and to acquire the ability to later take a fresh look at the transcripts ${ }^{[32]}$. Two months later, the investigator read all transcripts (sorted by focus group) and analysed them for related themes within each focus group ${ }^{\text {[37-39]. }}$. The transcripts and themes were re-visited one month later. A research assistant also read all transcripts and, independent of the investigator, noted related themes within each focus group. The investigator and research assistant compared their themes, discussed any theme that only one of them recognised, and came to consensus on whether it should remain a theme. The investigator and research assistant then made independent thematic comparisons across the four focus groups and compared their results.

\section{Findings}

The research findings are presented first by focus group and then a thematic comparison across the focus groups.

\section{Parents of preschoolers}

Four mothers of four females with Down syndrome between the ages of 3 and 5 participated in this focus group interview. The mothers saw their children as naturally active and were determined to keep their children physically active to prevent obesity. The preschoolers' primary forms of physical activity were the time they spent in therapy and at recess during the school day (special education preschool programmes at public schools) and the structured and unstructured play activities parents provided at home. The mothers estimated their children were sedentary an average of 2-3 hours per day, which was less than the average time per day they were physi- cally active. The parents felt they had no influence on the amount of physical activity their children receive or the activities they participate in at school. The activities they provided at home included trips to the park or playground, playing ball with parents and siblings, organised dance and gymnastics lessons, and free play in the yard.

The two most salient themes for this group were the prevention of obesity and the desire for an organised physical activity intervention. Prevention of obesity was addressed through diet and physical activity. The mothers controlled their children's exposure to sweet foods and encouraged the children to eat a variety of fruits and vegetables each day. Each of them made sure their child was physically active as much as possible each day. One mother said,

\section{Physical activity is very, very important for our children. As they get older, they probably won't initiate it on their own. And, with all their other problems, we know that leads to obesity. It is very important to keep them active, keep them mov- ing, keep them learning, and keep them doing.}

Another mother said, "She is always active now and she will always be active. She will Jazzercise with me. She'll dance. She will always do something. It's my mission. It's preventative medicine."

The mothers felt it was rather easy to keep their children active during their preschool years. However, they worried about the years to come. One mother said the following and received agreement from all of the other mothers,

\section{I think the problem is going to come. Right now, they are children and they are so active, and they are always playing. When our kids are 10 years old or so and they don't want to go out and play and they don't have peers that they can keep up with, we're going to have to hunt for things for them to do and that we can get them to do.}

One mother suggested, "It would be nice if we had some kind of structured programme that we could take them to that had a variety of things they could do now and that they could learn to do." All mothers agreed with this suggestion and added the child's sibling(s) needed to be involved in such a programme. They felt the sibling(s) needed to be involved in the physical activities to motivate the child with Down syndrome and to foster a helping relationship with the child with Down syndrome. The mothers stressed their need for such an organised intervention programme to be led by professionals. They acknowledged that if such a programme existed, they would have participation barriers such as finding time for it and working in the siblings' other needs and activities. 


\section{Parents of elementary-age children}

Four mothers of three males and one female with Down syndrome between the ages of 7 and 9 participated in this focus group interview. The mothers of elementary-age children with Down syndrome saw their children's interests in physical activity wane as the gap between their motor skills and the motor skills of their non-disabled peers widened and the number of appropriate community-based programmes decreased as their children aged. One mother said, "I think as they get older we'll see an even greater separation. The other kids are already becoming so much more proficient with their motor skills that it's hard now to find a group that he can play with." Another mother said, "Socially, the typical kids are very accepting as long as it's not a competitive activity."

The mothers felt that they had much influence on their child's health in terms of keeping them well, the foods they gave them, and the amount of unstructured physical activity they provided around the schedules and needs of all family members. Most of the children's organised activities came through physical education and recess at public schools; one child enrolled in organised lessons outside of school. One mother reported her child initiated playing outside daily. Three of the four children were described as followers of physical activity that is modelled by or initiated by other family members, especially siblings. One mother noted, "My daughter will walk away from the television if you tell her that her brother is going to take her outside to jump on the trampoline." Three of the mothers said that, unless the sibling is there to encourage physical activity, if their child has a choice between a sedentary activity and a physical activity, then their child will always chose the sedentary activity. One mother explained, "I think they are very visual and they are very present. It's this moment and what do I see."

The mothers said that they did not have the time to provide a structured physical activity programme on a regular basis, although they realised there would be numerous benefits from such a programme. According to one mother,

\section{If we're going to do a physical activity, then I'm going to have to supervise it, and I can't aban- don everyone else and their needs to supervise his physical activity for three hours everyday. It's just not possible. So, I give him a book or put him at the computer or the television where I know he will stay busy and safe while I'm doing other things.}

All of the mothers agreed they needed someone else to provide structured physical activity for their child. They were concerned that there was a lack of appropriate physical activity or exercise programmes that cater to their children or have staff members knowledgeable enough to work with them. Another concern was that many community-based programmes last only for one season, which ends by the time their children are just beginning to learn the activities. The mothers also noted that, although their children are 79 years old, they were not potty-trained and such limits them from enrolling in some programmes. One mother said, "We may never accomplish the potty-training goal. But, that doesn't eliminate the need to participate in organised physical activity programmes." Other barriers to participation in organised programmes were costs and other family members' schedules.

The mothers had an interest in their children participating in physical activities with and without other children with Down syndrome for immediate and long-term health benefits and for socialisation with others. One mother said,

I think physical activity is very important and you should get them in a routine of doing physical activity so that when they become an adult it will be a habit and something they'll want to do because they are great at following routines. And, exercise is very important for their overall health down the road.

\section{Parents of teenagers}

Five mothers of five males with Down syndrome between the ages of 14 and 22 participated in this focus group interview. All of the mothers in this group reported their children received physical education through public school enrolment and also sometimes participated in structured group and unstructured group physical activities outside of school. The mothers agreed there were many challenges to participation in after school community-based physical activities, including motivating their children to be physically active. All of their children wanted to participate in inclusive activities and refuse to participate in special needs activities such as Special Olympics. The mothers observed many commonly found traits of typical adolescents in their children with Down syndrome, such as wanting to be with their friends, wanting to belong to a sports team, and a desire for competitive sporting opportunities. One parent shared, "My son wants the outs and his wants the score. He wants to get out and get other people out", referring to special leagues teams that may not keep track of outs and scores. Another parent observed, "Maybe it's not there for them athletically, but they want the same things." Another related, "My child just doesn't have the options for organised activities that other kids have."

The mothers noted a need for their children 
to have previously learned an individual sport because at this age, their motor skills did not match their cognitive skills; they were too strong physically for the special needs leagues and teams or they understood enough to know the rules were being modified and they did not want to play with modified rules or with children half their age. One mother said,

If someone had come to me years ago and said 'Get your child with Down syndrome involved in an individual sport', that would have helped so much. And, I think as adults many of us are that way. We'd rather compete against ourselves and being good at an individual sport helps us not have to rely on finding enough people to make a team and then find a challenging team to compete against.

Another mother said,

That is one of my biggest concerns because my child is so strong, so agile, and so able to play with kids his age physically and too strong for kids that are his age mentally, so there's no fit for him in an organised team activity.

Another mother added,

My son has the mental skills but he could never play on a school team because it is so competitive. He's just not at that level at all. And there's no in-between. There's school and there's sports for kids with special needs and he wants no part of the rule adaptations because he understands the regular rules.

Another mother concluded this discussion with, What I'm hearing is that the problems that our children have with physical activity are not a consequence of their disability, they are a consequence of the outer world not providing opportunities for everybody. Not just kids with Down syndrome but all the other kids who are not terribly athletic.

The mothers noted the importance of physical activity on their children's immediate and future health.
I worry about the long-term effects of not being as active now because they do tend to become overweight later in life. If he's not very active now, it's going to be more difficult for him to be active when he's older. I can see now that at 15 years old he's slowing down from when he was 10 and that makes me very sad.

The mothers wished they had better prepared their children to be physically active at this age but they said when their children were younger they were too busy with other issues, such as learning to walk and talk and then becoming successful in the classroom. One mother concluded,

And you feel like you have to be so smart. You feel like there's a way to implement this but what is it? As he gets older, I find it harder to know how we can use his interests and channel them toward things that he needs. And, it's complicated to know where you draw the line and just let him be.

\section{Mixed age group}

Three mothers and five fathers of three females and five males with Down syndrome between the ages of 5 and 14 participated in this focus group interview. All of the children represented by the parents in this focus group were enrolled in physical education or adapted physical education at their local public schools. All but one of the children was also enrolled in a structured community-based physical activity or sport. All but one of the parents said that their child was willing to participate in physical activity if encouraged to do so and especially if a sibling or peer was involved; however, most parents said that their child did not initiate that participation. Most of the parents commented on their child's need to understand a reason for participation in physical activity prior to displaying willingness to participate in the activity. As one father explained,

I think with him there aren't many physical activi-
ties that mean anything to him by themselves. He
will not go out and swing or ride a bike for long
periods of time. Anything he does has to involve
somebody else or relate to a game. I can't recall
any physical activity that he enjoys just for the
sake of being physically active. What we think he
ought to enjoy and have fun with, he doesn't see a
point in so he stops doing it.

The parents in this focus group described social interaction outcomes as the primary reason why their children will participate in physical activities. One father said,

Recognising that the social part has to go with it
has been really important for us to make anything
happen. He ties all physical activities to social
events. He won't do any physical activity on his
own and he won't do anything he perceives as
just exercise. But, if there's somebody to play frisbie
or go hiking or go bike riding with him, he'll go
and enjoy it for as long as the other person is there
to participate with him.

All but one of the parents said socialisation with siblings and peers was most desired by their children. All of the parents shared a hope that their children would be physically active throughout their lives for physical, mental, and emotional health benefits but they expressed a need for parent education regarding physical activities that can be implemented in the family setting. One father said,

I think a number of people here have said that we don't really have enough information often to know how to make the best decisions ourselves. Some doctors are terrific about certain parts of 
it, but my experience is, having been a physician myself, we don't know everything either so getting good information from a professional who can guide us with physical activity and exercise interventions would be really helpful.

As a group, the parents came to consensus on how that information might be presented to them. They thought that it should be given out by the school during regular meetings, should be appropriate for their child's age, should include a range of individual activities that would interest the child with Down syndrome and group activities for the family, and should include very specific activity descriptions and illustrations. Additionally, they thought their children would benefit from keeping an activity or exercise log and submitting it to a teacher or other supervisor on a regular basis. The parents felt this would help them prepare their children to have the motor skills necessary to be physically active as teenagers and adults, either on a team or through an individual sport or a recreational or fitnessoriented activity. One parent observed, "We're slowly starting to see that, in the team sports, our son will not be able to play because he is so small and they are so rough." Another parent commented, "Right now, the gap is widening no matter what we do." A mother concluded,

I think the parent education suggestions that we just came up with would be very beneficial. I can see that as they get older you would like for them to have the motivation to stay physically fit. And my concern is finding a niche that would fit their abilities, give them self-esteem, and that they would enjoy doing without us having to make them do it. Right now, I don't have any ideas for how to do that or what it would be.

\section{Thematic comparison across focus groups}

Across all focus groups, parents involved their children in physical activities at different ages for immediate and long-term health benefits and social interaction, but none of them thought their child was getting a sufficient amount of physical activity. Parents in all focus groups except for the preschool group said that their children will choose to be sedentary unless they are motivated by siblings or peers to be physically active or unless they understand the point of the activities. Social interaction through physical activity was a particular desired outcome of the children represented in the elementary, teenage, and mixed age focus groups and a main reason that the children participated in physical activities. The teenage focus group and the parents of teenagers in the mixed age focus group observed a need for their children to develop skills in individual sports as a way to become successful in a sport without the requirement for ability-matched teammates and opponents. Parents in all four focus groups expressed a need for physical activity guidance from professionals or increased availability of appropriate community-based physical activity programmes for their children.

\section{Discussion}

Beyond the indications that all of the children and adolescents represented in this study participated in physical education at school and most of them also engaged in community-based and home-based physical activities, there were four themes repeated across focus groups: (1) all parents believed that participation in physical activity has immediate and long-term positive health impacts on their child with Down syndrome, and most of the parents thought their child would benefit from being more physically active, (2) most parents observed that their child participates in physical activities primarily for social reasons, most notably to be with their peers with or without Down syndrome or to be with their sibling(s), and that without such motivation their child would choose sedentary activities, (3) parents of teenagers identified a need for their child to learn an individual sport to have sporting opportunities that do not require ability-matched teammates and opponents, and (4) parents recognised their need for help from physical activity specialists through either parent education regarding home-based physical activity programmes or an increase in appropriate community-based physical activity programmes for their child with Down syndrome.

Heller, Ying, Rimmer and Marks ${ }^{[40]}$ saw a need to educate caregivers of adults with cerebral palsy on the benefits of physical activity. Frey et al. $^{[24]}$ found that parents of children with mental retardation were aware of the benefits of physical activity but did not actively encourage such activity. In contrast, all of the parents in each of the four focus groups expressed an understanding of the need for their child to be physically active throughout his or her lifetime for immediate and long-term health benefits. As one parent concluded,

\section{I want him to be healthy enough as an adult to be independent. That's really the ultimate goal. And, exercise is a huge part of that. And, like every- one here has said, exercise will benefit him in all aspects of his health so it is a critical component of his life.}

This is particularly significant given the findings of Trost, et al. ${ }^{[26]}$ that the value parents give physical activity correlates with their support of their children's participation in physical activities. It is feasible that, because the parents in this 
study valued physical activity and exercise, then they will continue to provide related opportunities for their children with Down syndrome. In fact, most of the parents in this study thought their child would benefit from being more physically active. The parents described their need for either parent education regarding home-based physical activity programmes or an increase in appropriate community-based physical activity programmes for their child with Down syndrome.

The parents' comments support Rimmer's ${ }^{[41]}$ suggestion that there is a need for greater emphasis on community-based programmes which promote health wellness issues for individuals with disabilities. In the United States, there are currently more community-based physical activity programmes for individuals with disabilities than ever before. However, offerings for children, youth, and adolescents are primarily restricted to special needs programmes such as Special Olympics and Miracle League, which, according to the parents in this study, do not meet either the cognitive or the physical needs of their children with Down syndrome or they do not last long enough for their child to become successful. It is difficult to conquer the challenges of finding teammates that have similar cognitive and physical abilities, even in a large metropolitan area that has special leagues (e.g., Special Olympics and Miracle League), church recreation teams, and park and recreation programmes for individuals with disabilities.

The parents in one focus group identified a need for home-based interventions. Home-based physical activity interventions have been found effective with 7- to 14-year-old children with cystic fibrosis $^{[42]}$, children with mental retardation $^{[43]}$, and infants and toddlers with Down syndrome ${ }^{[44,45]}$. Programmes that are guided by family systems theory hold much potential for immediate and long-term success ${ }^{[46]}$.

Many of the suggestions given by the parents in this group were components of other successful home-based programmes for children with Down syndrome ${ }^{[44,45]}$, such as: individualised assessment; individualised written exercise plans that could be implemented within the family context and allow for choices and substitutions; written and pictorial descriptions of the exercises; an implementation log; and a system for feedback and reinforcement. One mother wrote this summary comment on the transcript of the elementary age focus group, "In this realm of physical activity it's all about cost, location, timing, meeting programme requirements, and often 'Do I have to invent/reinvent the wheel to make it happen?'”. A home-based intervention as just described could reduce participation costs. Location and timing of implementation would be the family's choice because the intervention would be home-based and implemented within the family context. Such a programme could be administered by the physical educator at the child's school. It could relate to the child's special education goals and objectives, align with the school's physical education curriculum, and foster the development of lifetime fitness and leisure skills.

Thematic analysis of the transcripts from the elementary, teenage, and mixed age focus groups yielded data that may seem contradictory. Many parents indicated that their children participated in physical activities and sports for socialisation with their peers and sibling(s). Over time, their children with Down syndrome became less successful during competition due to delays in their cognitive or physical development. The parents wished for programmes that better met their children's needs and suggested that participation in individual sports may provide success, increase in self-esteem, opportunity for leisure time activity, and health-related benefits. When the transcripts were reviewed collectively, it was obvious that, while an individual sport could match the physical and mental abilities of individuals with Down syndrome, it may not address their desires for social interaction through physical activity and sports.

Is there a way to capitalise on the quest for socialisation through physical activity? Some individual sports such as golf, skiing, climbing, cycling, bowling, swimming, and gymnastics can be played as competition against oneself or as competition against another person. For some individuals, dual sports such as tennis, racquetball, and badminton may be appropriate, particularly if there is a match of cognitive and physical abilities. Non-competitive activities such as inline skating, aerobics, and yoga can be group activities that may be of interest to individuals with Down syndrome, and they may find much success with these activities. The activities suggested here could be incorporated into the child's goals and objectives for physical education and related to an individualised home-based fitnessbased intervention.

There is support for this suggestion in the professional literature. Through an investigation of the activity levels of adult men and women with mental retardation, many of whom had Down syndrome, Draheim et al., ${ }^{[12]}$ found that 17 of the 23 characteristics of physical activity reported by their participants were individual sports and were the ones participated in by the highest percentage of study participants ( 4 others were team 
sports and 2 others were dual sports). Therefore, depending on the amount of exertion, individual sports and perhaps dual sports may provide socialisation through physical activity and provide individuals with Down syndrome sufficient vigorous activity to obtain exercise-related benefits.

\section{Conclusion}

Overall, the data presented in this article remind one of typically developing children, teenagers, and adults. In general, most young children are natural movers whose play is largely physical activity $^{[47]}$. Developmentally, older children and adolescents tend to surround themselves with their peers and select activities that have a strong social component ${ }^{[48]}$. And, in the United States, most adults lead physically inactive lifestyles and are either obese or overweight ${ }^{[51]}$.

The research study described in this article indicates that children and teenagers with Down syndrome are naturally active, due in part to their parents' support of such activity. However, because of barriers related to developmental delays, lack of appropriate community-based services, and a need for parent education regarding home-based programmes, such activity levels decrease or are expected to decrease over time. These decreases are common to adults with Down syndrome; prior research has consistently indicated that adults with Down syndrome lead physically inactive lifestyles, exhibit low fitness levels, and are either obese or overweight.

Frey et al., ${ }^{[24]}$ suggested that individuals with mental retardation may need specially designed programmes and training, a suggestion that was echoed in the current study. Future research should evaluate the outcomes of long-term individualised home-based physical activity interventions for children with Down syndrome. Additionally, educators, recreation specialists, and therapists should assist children and youth with their acquisition of skills used in individual and dual sports.
1. Fernhall B, Pitetti $\mathrm{KH}$, Rimmer $\mathrm{JH}$, McCubbin JA, Rintala P, Millar L. Cardiorespiratory capacity of individuals with mental retardation including Down syndrome. Medicine and Science in Sports and Exercise. 1996;28:366-371.

2. Fernhall B, Tymeson G, Millar AL, Burkett LN. Cardiovascular fitness testing and fitness levels of adolescents and adults with mental retardation including Down syndrome. Education and Training in Mental Retardation. 1989;24:133-138.

3. Pitetti KH, Climstein M, Mays MJ, Barrett PJ. Isokinetic arm and leg strength of adults with Down syndrome: A comparative study. Archives of Physical Medicine and Rehabilitation. 1992;73: 847-850

4. Pitetti KH, Climstein M, Campbell KD, Barrett PJ, Jackson JA. The cardiovascular capacities of adults with Down syndrome: A comparative study. Medicine and Science in Sports and Exercise. 1992;24(1):13-19.

5. Varela AM, Sardinha LB, Pitetti KH. Effects of an aerobic rowing training regimen in young adults with Down syndrome. American Journal on Mental Retardation. 2001;106:135-144.

6. Cronk CE, Chumlea WC, Roche AF. Assess ment of overweight children with trisomy 21. American Journal on Mental Deficiency. 1985;89: 433-436.

7. Melville CA, Cooper SA, McGrother CW, Thorp $C F$, Collacott R. Obesity in adults with Down syndrome: A case-control study. Journal of Intellectual Disability Research. 2005;49(2):125-133.

8. Piro E, Pennino C, Commarata M. Growth charts of Down syndrome in Sicily: Evaluation of 382 children 0-14 years of age. American Journal on Medical Genetics. 1990;7:66-70.

9. Prasher VP. Overweight and obesity amongst Down's syndrome adults. Journal of Intellectual Disability Research. 1995;39(5):437-441.

10. Rubin S, Rimmer JH, Chicoine B, Braddock D, McGuire D. Overweight prevalence in persons with Down syndrome. Mental Retardation. 1998 36:175-181.

11. Beange $H$, McElduf A, Baker W. Medical disorders of adults with mental retardation: $A$ population study. American Journal on Mental Retardation. 1995;99:595-604.
12. Draheim CC, Williams DP, McCubbin JA. Prevalence of physical inactivity and recommended physical activity in community-based adults with mental retardation. Mental Retardation. 2002;40:436-444.

13. Hoge G, Dattilo J. Recreation participation of adults with and without mental retardation. Education and Training in Mental Retardation and Developmental Disabilities. 1995;30:283-298.

14. Rimmer JH, Braddock D, Marks B. Health characteristics and behaviors of adults with mental retardation residing in three living arrangements. Research in Developmental Disabilities. 1995; 16:489-499.

15. Fujiura GT, Fitzsimons N, Marks B. Predictors of $\mathrm{BMI}$ among adults with Down syndrome: The social context of health promotion. Research in Developmental Disabilities. 1997;18:261-274.

16. Kosma M, Cardinal BJ, Rintala P. Motivating individuals with disabilities to be physically active. Quest. 2002;54:116-132.

17. Balic MG, Mateos EC, Blasco CG, Fernhall B. Physical fitness levels of physically active and sedentary adults with Down syndrome. Adapted Physical Activity Quarterly. 2000;17:310-321.

18. Tsimaras V Fotiadou EG. Effect of training on the muscle strength and dynamic balance ability of adults with Down syndrome. Journal of Strength and Conditioning Research. 2004;18:343-347.

19. Carmeli E, Kessel S, Coleman R, Avalon M. Effects of a treadmill walking programme on muscle strength and balance in elderly people with Down syndrome. Gerontology. 2002;57: 106-110.

20. Croce R, Horvat M. Effects of reinforcemen based exercise on fitness and work productivity in adults with mental retardation. Adapted Physical Activity Quarterly. 1992;9:148-178.

21. Heller T, Hsieh K, Rimmer JH. Barriers and supports for exercise participation among adults with Down syndrome. Journal of Gerontological Social Work. 2002;38:161-178.

22. Heller T, Hsieh K, Rimmer JH. Attitudinal and psychosocial outcomes of a fitness and health education programme on adults with Down syndrome. American Journal on Mental Retarda tion. 2004;109:175-185.
23. Jobling A. Life be in it: Lifestyle choices for active leisure. Down Syndrome Research and Practice. 2001;6:117-122.

24. Frey GC, Buchanan AM, Rosser Sandt DD. "I'd rather watch TV": An examination of physica activity in adults with mental retardation. Mental Retardation. 2005;43:241-254.

25. Davison KK. Activity-related support from parents, peers, siblings and adolescents' physical activity: Are there gender differences? Journal of Physical Activity and Health. 2004;1:363-376.

26. Trost SG, Sallis JF, Pate RR, Freedson PS, Taylor WC, Dowda M. Evaluating a model of parental influence on youth physical activity. American Journal of Preventive Medicine. 2003;25:277-282.

27. Prochaska JJ, Rodgers MW, Sallis JF. Association of parent and peer support with adolescent physical activity. Research Quarterly for Exercise and Sport. 2002;73:206-210.

28. Anderssen N, Wold B. Parental and peer influences on leisure-time physical activity in young adolescents. Research Quarterly for Exercise and Science. 1992;63:341-348.

29. Biddle S, Goudas M. Analysis of children's physical activity and its association with adult encouragement and social cognitive variables. Journal of School Health. 1996;66:75-78.

30. Dempsey JM, Kimiecik JC, Horn TS. Parental influence on children's moderate to vigorous physical activity participation: An expectancyvalue approach. Pediatric Exercise Science. 1993; 5:151-167.

31. Borra ST, Schwartz NE, Spain CG, Natchipolsky MM. Food, physical activity, and fun: Inspiring America's kids to more healthful lifestyles. Journal of the American Dietetic Association. 1995;95: 816-818.

32. Bogdan RC, Biklen SK. Qualitative research for education: An introduction to theory and methods ( $4^{\text {th }}$ ed). Boston, MA: Allyn and Bacon; 2003.

33. Kvale S. InterViews: An introduction to qualitative research interviewing. Thousand Oaks, CA: Sage; 1996.

34. Krueger RA, Casey MA. Focus groups: A practical guide for applied research. $3^{\text {rd }} \mathrm{ed}$. Thousand Oaks, CA: Sage; 2000. 


\section{REPORTS}

35. Lincoln YS, Guba EG. Naturalistic inquiry. Newbury Park, NJ: Sage; 1985.

36. Guba EG. Criteria for assessing the trustworthiness of naturalistic inquiries. Educational Communication and Technology Journal. 1981;29(2): 75-91.

37. van Manen M. Researching lived experiences: Human science for an action sensitive pedagogy. London, ON: Althouse Press; 1990.

38. Wolcott HF. Transforming qualitative data: Description, analysis, and interpretation. Thousand Oaks, CA: Sage; 1994.

39. Wolcott HF. Writing up qualitative research. $2^{\text {nd }}$ ed. Thousand Oaks, CA: Sage; 2001.

40. Heller T, Ying G, Rimmer JH, Marks BA. Determinants of exercise in adults with cerebral palsy. Public Health Nursing. 2002;19:223-231.

41. Rimmer JH. Health promotion for people with disabilities: The emerging paradigm shift from disability prevention to prevention of secondary conditions. Physical Therapy. 1999;79:495-502.

42. Tuzin BJ, Mulvihill MM, Kilbourn KM, Bertran DA, Buono M, Hovell MF, Harwood IR, Light MJ. Increasing physical activity of children with cystic fibrosis: A home-based family intervention. Pediatric Exercise Science. 1998;10:57-68.
43. Stanton KA. Effects of a parent training programme involving behavior modification techniques to increase the walking behavior of children with mental retardation: A family systems approach [dissertation]. Charlottesville: University of Virginia; 1995

44. Sayers LK, Cowden JE, Sherrill C. Parents' perceptions of motor interventions for infants and toddlers with Down syndrome. Adapted Physical Activity Quarterly. 2002;19(2):199-219.

45. Sayers LK, Cowden JE, Newton M, Warren B, Eason B. Qualitative analysis of a pediatric strength intervention on the developmenta stepping movements of infants with Down syndrome. Adapted Physical Activity Quarterly. 1996;13(3):247-268.

46. Kozub FM. Adapted physical activity programming within the family: The family systems theory. Palaestra. 2001;17(3):30-38.

47. Gallahue DL, Ozmun JC. Understanding motor development: Infants, children, adolescents, adults. $6^{\text {th }}$ ed. Boston, MA: McGraw-Hill; 2006.

48. Coakley JJ. Sport in society: Issues and controversies. Boston, MA: Times Mirror/Mosby; 2001.

49. Rimmer JH, Heller T, Wang E, Valerio I. Improvements in physical fitness in adults with Down syndrome. American Journal on Mental Retardation. 2004;109:165-174.
50. Draheim CC, Williams DP, McCubbin, JA. Physical activity, dietary intake, and the insulin resistance syndrome in nondiabetic adults with mental retardation. American Journal on Mental Retardation. 2002;107:361-375.

51. Prevalence of Overweight and Obesity Among Adults: United States, 1999-2002. [cited 2005 Dec 7]. Available from: http://www.cdc.gov/nchs/products/pubs/ pubd/hestats/obese/obse99.htm

\section{Acknowledgements}

This study was approved by the Institutional Review Board of the University of Alabama at Birmingham and was funded, in part, through a seed grant from the Research Consortium of the American Alliance for Health, Physical Education, Recreation, and Dance.

Received: 8 December 2005; Accepted 03 May 2006; Published online: 30 July 2007. 